\title{
Fashionable curiosities: extreme footwear as wearable fantasies
}

Dr Anna Catalani

School of Architecture and Design

University of Lincoln

Brayford Pool

Lincoln LN6 7TS, United Kingdom

Email: annacatalani@gmail.com

Currently, Anna Catalani is a Reader based in the School of Architecture at the University of Lincoln, United Kingdom. Her research interests and expertise are focused on the field of material culture; heritage and identity formation. Anna has a $\mathrm{PhD}$ in Museum Studies, awarded by the University of Leicester. 


\begin{abstract}
This paper considers an aspect of the material culture fashion, focusing on shoes. Like clothes, shoes are used every day: they are essential objects that primarily allow people to perform daily and socially accepted activities, walk comfortably and adorn the body in a fashionable way. Furthermore, shoes are associated with the idea of individuality and can be highly practical or decorative, depending on their design and fashion style.
\end{abstract}

With regard to their style, one phenomenon emerging in high fashion is that of the “impossible-to-wear shoes”: exhibitions and fashion shows staging designers’ bizarre shoes are becoming more frequent. During these shows, the spectators are presented with an unusual variety of footwear (e.g. heelless shoes; shoes without soles; fish-shaped shoes). These shoes are not made to fit the individual. On the contrary, their shape and forms are imposed on the individuals.

This paper explores the extreme, impossible-to-wear shoes and considers the visual statements they make about contemporary society, women and femininity. I will argue that impossible-to-wear shoes are puzzling yet charming objects, epitomizing a spectaclecentered society: they are part of unexpected and personal performances, which blend the boundaries of fashion and art and allow the wearers to shift from an ordinary "self” to the extraordinary “other”.

Keywords: identity; material culture; extreme shoes; society of the spectacle. 


\section{Introduction}

This paper addresses the material culture of women shoes and, precisely, the extreme, "impossible-to-wear" shoes. "Impossible-to-wear” is an arbitrary term, which does not indicate that these shoes are not wearable. Instead, it aims to emphasize their unique and extreme design features that do not permit labeling them as conventional and practical footwear, or restricting them to an "adequate system of classification” (Baudrillard, 2005: 1).

Previous studies have considered the ways in which fashion, clothes and accessories (including shoes) are used to empower and represent women socially (Barnard, 2002; Guy and Banim, 2000). Furthermore, although the phenomenon of the extreme shoes is not new, either historically or culturally, it is only in recent years that such shoes have become more popular, both in the high fashion and the social, popular scene (Steele and Hill, 2012). This has opened up the opportunity to understand further the post-modern fashion discourse, which tends to simulate and exasperate the values and principles of beauty, power and status through the notion of a spectacular play (Baudrillard, 2005, Huizinga, 1971, Debord, 2006).

In this paper, I intend to define the "impossible-to-wear" shoes and consider the visual statements they may make about contemporary society, women, their identity and their femininity. To that end, this paper is structured into three main parts: in the first part, I consider impossible-to-wear shoes within the context of material culture and fashion studies, in order to understand how they reflect and construct the culture of which they 
are a part; the second section examines the society of the spectacle and the idea of playful fashion so as to outline the nexus between human playfulness and the fashion designers' creativity; in the third and final part, I argue that extreme shoes are the products of the society of the spectacle and, as such, are very seductive and challenging objects. They are contemporary curiosities, which consent the shift between the ordinary and the extraordinary; therefore, they allow women to step into a visually playful (but not necessarily empowering) fantasy-world.

\section{Defining the impossible-to-wear shoes}

My interest in shoes, including extreme footwear, is longstanding. Like many women, I consider shoes as key, fashionable accessories that are extremely needed and very much desired. In particular, I am fascinated by those shoes that break the conventional canons of aesthetic and practicality in the name of eccentricity and appearance: throughout this paper, I am interested in exploring how contemporary extreme, bizarre shoes can contribute to the understanding of modern society and the female discourse.

I first encountered a pair of extreme, impossible-to-wear shoes while walking to work. As I was heading to Manchester’s Piccadilly railway station one busy, rainy Monday morning three years ago, my attention was suddenly grabbed by a pair of Marc Jacobs’ blue shoes with inverted heels: they had been placed carefully on a cream drape, cascading elegantly in the right corner of the window of an Oxfam shop. Although there were all sorts of randomly assembled objects in the same display, this pair of shoes stood out, not only for the unusual morphology, but also because they had been gently and 
delicately laid out in a individual corner. As I was trying to make sense visually of this unusual pair of shoes, I began to think about their owner; what could have urged her to buy such a pair of curious shoes in the first instance? Was it the inverted-heel feature? Had it been the brand or the designer? Or were these shoes a gift for an unconventionally stylish lady? Where would she have worn them and what could have been the reason for giving them away? All these questions prompted me to reflect on the relationship between women and shoes, especially a new pair of shoes, which can, indeed, be very powerful and emotionally fulfilling.

As with any other type of object, shoes are meaningful, personal and symbolic entities: Susan Pearce states that "as humans we are able to feel strongly and bitterly about the objects around us and the symbolic meanings which they are capable of carrying” (1997: 2). This is because objects tangibly represent our deepest desires and fantasies, or our everyday needs. Often, the possession and display of owned objects help us project particular features of our persona to the outside world; for instance, we tend to display the souvenirs of our travels in the most visible spots at home not only to symbolically freeze a past leisure moment, but also because we feel the urge to reveal to our visitors who we are, what we like and where we have been (Woodward, 2007). Accordingly, a (new) pair of shoes (such as the Mark Jacobs’ pair in the Oxfam shop) can reveal much “about the constructedness of individual identity" [through] the impulse and satisfaction for "selffashioning and self-presentation” (Emberley, 2001: 4).

Choosing a pair of shoes is a very personal act and, for many women, can be almost a 
ritual in its own right: the conscious choice of the "right" pair of shoes can aesthetically complete an outfit and help make a visual statement about themselves and how they wish to be perceived by others (Barnard, 2002; Goffman, 1990; Tseëlon, 2001). In fact, shoes are associated first and foremost with the notion of distinctiveness, starting with the very basic key concepts of individuality: shoes may define, for example, a social class (like the chopins in the past), a style (e.g. “classic”) or personal fashion preferences (e.g. a Vivienne Westwood design over a Chanel design) (Huey and Proctor, 2007; Riello and McNeil, 2006).

Therefore, a new pair of shoes that we feel really represents us not only can be longed for and desired eagerly, but once owned, it can be jealously kept, carefully packaged in a shoe-cabinet and possibly worn (and exhibited) only on occasions considered worthy of the pain. Furthermore, shoes can have a predominant practical or decorative feature: more than any other wearable objects, shoes can make people look distinctive and can reinforce the contemporary need not simply to "find oneself but to invent oneself” in society (Svendsen, 2006: 143).

Exhibitions, fashion shows and media personalities, staging bizarre and extreme designer shoes (such as the singer Lady Gaga; the heiress Daphne Guinness or Carrie Bradshaw, the fashion-addicted character of the TV series Sex and the City) are becoming more frequent. Potential customers are presented with atypical, almost endless (and often prohibitive in price) types of footwear: high-wedged plastic shoes; pure gold sandals; shoes embellished with peacock feathers; shoes without heels; lobster-claw shaped shoes; 
shoes with inverted heels; shoes without soles; fish-like shoes; or even pumps with guns for heels.

The shapes of these aforementioned shoes are very unusual, because they do not fit the conventional idea: each pair is a unique piece of a personal museum collection, of which we, as visual consumers, often struggle to make sense and classify properly. This is because these shoes belong to "a world of objects that changes before our eyes [and hence, it has become almost impossible to] arrive at an adequate system of description” (Baudrillard, 2005:1). Extreme shoes have been conceived, designed and produced to express primarily the designers' creativity. Indeed, through their unusualness, these shoes symbolize novelty while simultaneously provoking desire and curiosity in the stunned spectators. As Kobi Levi (an Israeli-born footwear designer) explains, extreme shoes are “a wearable sculpture, [which becomes] 'alive' with/out the foot/body”. ${ }^{1}$ They "combine the essence of daily objects with the shape of shoes” because, according to Levi, shoes must be easily relatable while also being “sexy, creative, funny and inspiring”. ${ }^{2}$

Similarly, in relation to contemporary footwear designs, Huey and Proctor stress that, because of their unique features, extreme "shoes have the power to seduce us, move us and empower us. They can fulfill our fantasies and help us to escape from reality, possibly more than shoes that fit within our conventional style and function criteria” (2007:6). Certainly, extreme shoes are not made to fit the individual. On the contrary, their shape and form are imposed on the individual: they are not designed necessarily to 
make women look their best; nor have they been made to visually enhance women’s outfits. Instead, they have been designed to make women who wear them to look, feel and aspire to be different from anybody else. Consequently, they are a sort of postmodern status symbol.

In the contemporary fashion scene, there are several examples that epitomize the difficulty of wearing extreme shoes. For instance, the dramatic tumble of Naomi Campbell on the catwalk in 1994 while wearing a ten-inch pair of blue mock-crock platform shoes designed by Vivienne Westwood is well known. This episode generated various debates around towering shoes (and extreme clothing in general) and the risks that such shoes were posing to the health and safety of models, and, subsequently, of those women who buy and wear such shoes (Vartanian, 2012). However, relevant debates and protests have not stopped the media and fashion industry supporting fashion designers in producing and promoting this kind of shoes, which have become the trademark of a spectacular post-modern society, made by “a complex choreography of interactions” (Sudjic, 2009: 54). The original, functional feature of shoes (to protect the feet, to allow individuals to walk more or less comfortably on hard surfaces and to complete, visually, an outfit) has become secondary while extreme shoes, as objects of post-modern fashion, have acquired new meanings (the "funny”, “curious” shoe) that allow them to fit into new visual and cultural classifications (e.g. the art-design, spectacular object) within a spectacular society.

Within the contemporary context of the fashion industry, shoes primarily are objects of 
fashion and, simultaneously, products of the spectacle society. Extreme, impossible-towear shoes reflect a fashion trend that aims to offer a spectacular product; a captivating and artistic image of a commodity. Its functionality lies in its playful spectacular nature. Within this discourse, the notion of the shoe becomes subject to a negotiation of the meanings of the image or of the product between the fashion industry, the designer and the consumer. Within the context of this article, I will focus primarily on the discourse of the spectacular product and the statements made subsequently about contemporary women and society. ${ }^{3}$

\section{The society of the spectacle and the playful fashion}

In 1967, the French theorist Guy Debord published The society of the spectacle, a critique of the French society of the time, in which he discussed the modern-day capital, cultural imperialism and its role in mediating social relationships. Throughout the article, Debord denounced an image-centered society, in which appearance was crucial and where social authenticity and values had been replaced by their representations, with the spectacle being the system regulating such representations.

Indeed, central to Debord's work is the idea of the spectacle not only as "a collection of images, [but rather as] a social relationship between people [...] mediated by images” (2006: 7). Through images, the spectacle falsifies and emulates reality; at the same time, the spectacle is a product of the reality itself (e.g. mass media). Therefore, the society of the spectacle is absorbed into a fantasy world that "spatializes time and destroys 
memory” by capitalizing on images and focusing on the new and innovative commodity (Evans, 2007: 67). Furthermore, the society of the spectacle supports the creative consumption of such images: in it, "meanings are produced, altered and managed at the level of use by people who are active producers of meaning [and] rather than being inherent in the commodity, meaning and value are constructed through the actual usage” (Barker, 2012: 51). It is the culture of implosion and simulation, defined by image production, aesthetic self-consciousness, ambiguity culture of images and transgression (Debord, 2006).

Additionally, the idea of play (through the image/appearance of "ambitious playfulness" or "playful competition”) is a key feature of the society of the spectacle: play permeates all human, spectacular actions, which are also social in nature (Huizinga, 1971). In other words, as human beings, we are part of a social structure and we communicate and interact with each other through different, visual bodily means: our facial expressions, clothing and posture. Through our bodies, and what we use to cover or visually enhance them, we can negotiate playfully how we present ourselves to others, while our “symbolic actions construct and deploy a shared cultural vocabulary or idiom of bodily communication” (Barker, 2012: 120).

Human actions involve the desire to play with our image and convey the impression that we want others to have of us. Moreover, where there is play there is also social meaning, negotiated between two parties/players: the message bearer and the receiver (Huizinga, 
1971). ${ }^{4}$ Therefore, we can state safely that all actions are simultaneously social and playful performances, with the aim of going beyond achieving the primary purpose of the action (e.g. the gesture) to build, maintain and transmit a certain desired impression of the self to others (Goffman, 1990; Tseëlon, 2001).

Moreover, besides being social, the idea of play - or being playful - tends to be beautiful, enchanting and captivating. In the context of the society of the spectacle, play abolishes what is ordinary, since it is driven by those images that entail the "fun and spectacular element and can largely be derived either from a contest for something or from a representation of something” (Huizinga, 1971: 13). These features (beautiful, enchanting and captivating) are also characteristics of extreme, impossible-to-wear shoes.

As with any other type of object, extreme shoes are influenced by a specific cultural framework that determines how we make sense of shapes, colors, textures and strengths. This framework defines how we make use of and live with things: in it, all objects are social agents in the limited sense that they extend human action and mediate meanings between humans (Dant, 1999; Miller, 2010). Fashion shows and media events offer a formal cultural framework from which to understand extreme shoes: they are both trade and cultural occasions, which people (from the designers to the models to the spectators) primarily attend in order to be noticed (either by the media, the public or imageconsumers) or to be part of a spectacular, ephemeral experience. Such events are all about image and image-representation, characterized by excessive theatricality, which certainly 
aims to advertise the product (the shoes, the outfit, the celebrity) and the designer; however, they also strive to surprise, shock and fascinate the audience.

In this framework of staged events, clothing and women - accessorized through their bodies - become part of the spectacle, since the image production and representation occur through and upon them. As Suzanna Walters points out, women become spectators and, at the same time, "consumers of their very own image, their very own objectification" (1994:22). The human body becomes the message-bearing entity of "the spectacle” through the wearing of such spectacles (the extreme shoes in our case). It is in this context that extreme shoes are created and fulfill their spectacular function. In the post-modern, spectacular society, fashion has attached, but not fully assimilated itself, to "the partnership of art and fashion, in which some designers work within similar ideological and cultural circumstances as that of contemporary artists” (Taylor, 2005:

447). Therefore, several shared and inevitable crossovers exist between these two socially-instituted systems (Steele, 2012; Boodro 1990). For example, the playful element "appears to us as an intermission in daily life [both in fashion and in art], as a relaxation. [Play, both in fashion and art] adorns life, compensates for the deficiencies of life and in this respect is indispensable” (Huzinga, 1971: 28).

Undoubtedly, extreme shoes are ambiguous, playful and often curious objects, whereby stylistic emphasis is placed on the "aesthetic value of the designs" rather than on their function; therefore, their creators can fairly claim "the status of artists or artist-craftsman" (Crane 2001:149). Actually, impossible-to-wear shoes are stylistic experiments of 
extreme innovation: they aim to disrupt the traditional patterns of fashion production and defy the principles of everyday shoes, by creating a distinct separation between the beautiful and the useful (Hegarty, 2004). As the Dutch-born shoe designer Marloes ten Bhömer explains:

I am interested in designing objects that ignore or challenge conventions in order to make the product-design less generic [and hence] what really fascinated me is when you understand what the product is but at the same time it doesn't look like anything you have seen before (Huey and Proctor, 2007: 165).

Most of ten Bhömer' s creations are one-off designs: they are functional, crafted pieces of art that have been exhibited in museums and galleries, strengthening further the link between art and fashion. Certainly, many contemporary fashion designers are artistcraftsmen like ten Bhömer. As Susan Crane observes: while "artists use the skills of craftsman but the objects they make are often neither useful nor beautiful [fashion designers aim to] deliberately [...] subvert these values. [...] Their goal is to produce a work that is unique, totally different from other objects” (2001: 133). In this way, designers are not only able to produce ideas for trends, but are also part of the fashion network, whereby they acquire the acknowledged status of "The Designer”. The anxiety associated with this increases the pressure on the designers: creative talent and innovation are crucial elements for success, but spectacular ideas are also essential (Kawamura, 2005). 
Indeed, it is key for the designer to invent, surprise and disrupt trends: it is indispensable to make an impact on the viewers by creating spectacular objects, such as extreme shoes. For this reason, contemporary fashion designers subvert conventional (visual, functional) ideas in order to create stupor and admiration through curios and daring creations, for whom they assume to be contemporary, daring, fashion-conscious consumers.

\section{Wearable fantasies and women}

In order to be used as a means through which representation can occur, the body must first be re-experienced by its owner; it must be considered "narcissistically rather than merely functionally" and a new (or different) identity must be assumed by the individual (Ritzer, 1998:13). Only once the body is conceived in this way, can individuals adorn it freely with objects and indulge in visual, fashionable representations. Women (both buyers/users as well as visual consumers) are able to occupy a social, familiar role (e.g. the student; the model), but also to play around new chosen social roles through the use of new fashionable curiosities.

When pondering the society of the spectacle and its products, it is essential to consider all the parts involved. This means reflecting not only on the roles of the producers and executors of spectacular images, objects and curiosities, but also the consumers of such images and objects. As we have seen briefly, the designers play a key role in setting new trends through unusual, extravagant items. In turn, these permit endorsement and inclusion in the fashion world. However, the consumers of such trends are also essential players in the neomaniac fashion industry. The "consumers" category includes everyday 
people, who witness the unfolding of the society of the spectacle before their eyes on a daily basis, through fashion displays, TV images and shows, or fashion magazines.

Given the subject of this paper (the extreme, impossible-to-wear-shoes), the typology of (visual) consumers I have considered hereby are: women in their 30s who are well aware of the current fashion trends, and who have a strong interest in shoes and a stable job. As regular consumers of fashion images and fashion objects, this specific group provides an interesting snapshot on the perception of the impossible-to-wear shoes on behalf of everyday women and of how (potential) possession, visual consumption and/or use of such shoes allows them to shift between their ordinary self and extraordinary other.

Between July and December 2013, I conducted a set of semi-structured interviews with ten women. The selected participants are self-proclaimed shoe addicts and, in some cases, even shoe collectors. ${ }^{5}$ At the time of the interviews, none of the participants was working in the high fashion industry and none owned a pair of extreme shoes. All the interviews were conducted face-to-face and were structured around three main themes: personal relationships with shoes; perceptions and definitions of extreme shoes; possible uses of extreme shoes.

During the discussions, participants were asked to comment on seven photos of extreme shoes, ranging from double-edge boots to shoes without soles, and from architectural shoes to shoes made from meat. The shoes were chosen according either to their extreme 
features (e.g. sole-less boots) or unusual designs (e.g. animal-like shoes): there was also a mix of shoes that had been worn by well-known media personalities - hence more recognizable by participants - and less media-endorsed shoes. However, all the selected footwear shared similar spectacular, playful characteristics: they all featured a curious, unconventional element, whether this was a double-toe box, a missing heel or with a child's toy (like a slingshot) incorporated in the heel. Finally, all the shoes selected for this study were made by internationally-known designers - albeit at different stages of their careers- who had exhibited their work at international fashion shows or in museums. ${ }^{6}$ This was an important element for the study because it acknowledges that all the designers had achieved worldwide recognition not only from their peers, but also from the wider artistic and cultural community.

\section{PLEASE INSERT FIG. 1 AND 2 HERE}

Specifically, the images of the shoes were: a pair of clog-like shoes, without heels, made by leather (“Noheelsleathershoe”, Fig. 1; Designer: Marloes ten Bhömer); a pair of black heel-less PVC boots (Designer: Antonio Berardi); a pair of toucan-like shoes, with the orange beak transformed into a heel (“Toucan Shoes”, Fig.2; Designer: Kobi Levi); a pair of boots with back and front toe boxes (“Double Boot”; Fig. 3; Designer: Kobi Levi); a pair of leather and wood shoes, with the heel shaped as a slingshot ("Sling-Shot Shoes", Fig. 4; Designer: Kobi Levi); a pair of boots made from meat (Designer: Franc Fernandez); and a pair of sole-less boots, with a solid wooden support for the heel and the 
calves, with silky laces ("Sole-less boots"; Designer duo: Aminaka Wilmont). It is fair to add that the use of photos of extreme shoes (rather than the actual shoes) may have influenced the interviewees' responses, since they did not have the chance to feel or wear them.

\section{PLEASE INSERT FIG. 3 AND 4 HERE}

However, in this context, the use of photo-elicitation as a research method proved to be useful in identifying the personal meanings and values attributed by the participants to the shoes. Actually, as Douglas Harper explains, while conducting interviews that use photo-elicitation, "the key element is not the form of the visual representation but its relationship with the image under study” (2002: 19). Indeed, throughout the interviews, I was interested in understanding how participants would make sense of extreme shoes through images. Moreover, I wanted to discover the extent to which they would go to own a pair of these shoes, given that they all defined themselves as "shoe-lovers" or "shoe-addicts". 7 At the same time, I aimed to define the visual statements these shoes make about women and their femininity. Three main themes emerged from the individual discussions: Shoes as Art; Crafted Curiosities and Wearable Fantasies.

\section{a. Shoes as Art}

Participants considered the impossible-to-wear shoes as fantasy-like curiosities, almost surrealist art objects. Specifically, they associated the shoes presented with the idea of 
curious pieces of art, crafted by a skilled artist. In fact, the interviewees made repeated comparisons between extreme shoes and art objects seen in art galleries: the shoes were akin to works of art; conceptually challenging and beautifully executed. At the same time, the extreme shoes were perceived as surprising and aesthetically captivating items; part of a yet-to-happen, spectacular art performance and ready to become alive (and purposeful) only once worn by the right user/performer: "I think you can wear them only if you are a fashion follower because they are pushing the boundaries: it’s a piece of performing art!” - explained one of the interviewees in reference to the meaty boots by Franc Fernandez (P9, December 7, 2013). Through their art-like novelty and innovation, the images of extreme shoes encapsulated, in the participants’ eyes, the spectacularity of the post-modern fashion world that makes "the spectacle of enjoyment into the subject matter of the show itself” (Evans, 2009: 85). However, because the extreme shoes were regarded as art objects or components of an art performance, the participants also felt that this type of footwear requires an art-educated audience in order to be fully appreciated. Another participant clarified this point while examining the image of the sole-lees boots by Aminaka Wilmont: "these shoes need to be worn with an audience to be appreciated, in front of someone who can understand the art piece” (P2, July 5, 2013).

This manifested perception reiterated the ongoing, perennial debate about the problematic relationship between fashion and art. Although the debate acknowledges that fashion and art are both part of a visual culture (Steele, 2012), it also recognizes that fashion and art are different systems with different economic values and functions; fashion is an unscrupulous world, “tarred by the brush commercialism”, which exalts dreams and sells 
luxurious commodities (Getzy and Karaminas 2012: 10).

Moreover, while fashion often can be understood as an “elevated craft”, it remains largely a relational social phenomenon. As such, fashion generally presupposes imitation and it is driven by vanity; while art is transcendental and is often driven by a cause (Miller, 2007). Regardless, the extreme shoes considered in this research seemed to be perceived (although not acknowledged) by participants very much like objects caught inbetween the two worlds of fashion and art. This was due to the fact that extreme shoes can blend both features of the realms of fashion and art: even though objects of fashion (as a kind of beautifully crafted and spectacular footwear, created by international fashion designers, like for example the Sling-Shot shoes by Kobi Levi), such as extreme shoes, are unique. They are not easy to imitate as they are often one-off creations and, as art, they may carry an abstract, concealed meaning infused by the designer/artist - as in the case of the meaty boots by Franc Fernandez, who conceived and designed them as a visual statement about fighting for one’s beliefs.

\section{b. Crafted curiosities}

Throughout the interviews, participants were intrigued primarily by the unusual shapes and forms of the shoes: the playful, almost toy-like appearance of the scrutinized footwear made them question the images they had before their eyes. As one of the interviewees stated, extreme shoes like the Sling-Shot pair and the Double Boot were “like a visual joke” (P4, August 3, 2013) that she could not grasp. Although visually appealing, she expressed difficulty in thinking about those shoes in a conventional, 
functional manner. Likewise, another participant was particularly intrigued by the Noheelsleathershoe and the Toucan shoes. As she was trying to make sense of them visually, she also explained her dilemma: "I like these pairs but, to tell you the truth, I would not even know how to wear them!” (P6, September 6, 2013).

This uneasiness in slotting the extreme shoes into a specific and functional category (e.g. high fashion footwear) highlights a basic and shared struggle: participants could not make sense (neither visually nor conceptually) of the objects; they could not insert them into a known web of meanings. However, they could contemplate, with amazement, the curious images presented to them and recognize the value of the challenging design and craftsmanship. Indeed, these shoes, as bizarre, joke-like objects, seemed to epitomize fully the ideas of enjoyment and spectacle, idealized by the post-modern culture, whereby diversity and extraordinariness become particularly appealing (Svendsen, 2006). The extreme shoes depicted were perceived by participants as "special objects for very special occasions” (P1, July 5, 2013), beyond the reach of common people and available only to a few individuals with a very distinctive taste regarding fashion.

Furthermore, participants did not demonstrate any longing to possess these curios shoes but they expressed the intention to visually analyze and almost dissect them in order to make sense of them. The images of the impossible-to-wear shoes, besides arousing wonder, also elicited an instinctive recognition of the difference between the traditional yet fashionable shoe and the unexpected, curious shoe. This is because extreme shoes are “things with an attitude”. They are objects that imply the intentionality of their creators to set them apart from the more common and generic objects (Dant, 1999). These wondrous 
shoes are not made to be consumed by everyone; rather, they are made to be admired, cherished and played with by a selected group of shoe-connoisseurs.

\section{c. Wearable fantasies}

By looking at the images, participants could not identify any of the fashionable features usually sought in shoes (e.g. to fit the clothes style; to look professional at work) and they all used similar adjectives to define the extreme shoes (e.g. weird, bizarre, quirky, funny, happy, confrontational). However, although the interviewees felt that these shoes did not look comfortable enough, they all seemed to reach the same conclusion: by wearing such shoes, they thought that they would change, become special; as if these shoes had the power to make them feel "cool and eccentric”, "pretty unique” and "not too serious about fashion but aware of the newest trends” (P8, November 24, 2013).

Furthermore, when asked what they would wear with such shoes, the majority of participants fantasized about where they would wear the extreme shoes and provided detailed scenarios (e.g. the context, the occasion, the color and style of their outfits): ${ }^{8}$

"I would probably wear them only at home with my boyfriend" (P1, July 5, 2013; referring to the Sole-less boots by Aminaka Wilmont)

"I would wear them when I am alone at home; I would sit in my living room, in my favorite chair, wearing my favorite black dress, while admiring them 
on my feet” (P7, October 16, 2013; referring to the Sling-Shot Shoes by Kobi Levi; and Noheelsleathershoe by Marloes ten Bhömer)

"I would wear them on a night out with friends, or also, at a private party, with my friends, where everyone should dress up for the occasion” (P5, September 5, 2013; referring to the Heel-less boots by Antonio Berardi; Soleless boots by Aminaka Wilmont; and Toucan shoes by Kobi Levi)

“These shoes are for creative people. If I could afford them, I would wear them at an event where I am invited as a VIP person, like a designer” (P10, December 7, 2013; referring to the Meaty Boots by Franc Fernandez; Double Boot by Kobi Levi; and Heel-less boots by Antonio Berardi)

By visually stepping into the impossible-to-wear shoes, participants projected themselves into private (but not necessarily extravagant) roles and contexts, where they could reexperience their idea of fashion and personas and felt free to be weird, bizarre, quirky, funny and even confrontational, just like the shoes they imagined themselves wearing. Extreme shoes resurfaced the participants' hidden and transient self: a self “less subject to institutional construction and judgment [...] not given by formal recognition or occupation” (Miller, 2010: 19); a self they could choose, as along with the surroundings and the company, without having to address any given social or fashion expectations.

The idea of fashion as a vehicle for personal performances or for (public) fashion 
masquerades is not new. However, it may be useful to reiterate - in the context of this paper and in relation to extreme shoes - the key role played by fashion in drawing attention to the performing, playful nature of human identity and the need for individuals to “create a space from where one can play out desires and fears” (Tseëlon, 2001:3). Actually, as products of the society of the spectacle, extreme shoes represent the postmodern fashion rejection of traditions and given norms, in favor of emphasizing individual diversity and variability of styles. These, in turn, mirror a plurality of possible and unexpected personal narratives (Tseëlon, 2001).

\section{Concluding thoughts}

When examining impossible-to-wear shoes, we may be confused, perhaps enchanted, but certainly mesmerized by their bizarre extravagance. A new set of post-modern curiosities unravels in front of us and we, as the viewers of the first cabinet of curiosities, try to make sense of these new items by slotting them into a complex choreography of material and social interactions (Sudjic, 2009).

Throughout this paper, I intended to untangle this complex choreography of social interactions, as well as considering the visual statements such shoes make about women, their identity and their femininity. My starting point has been to look, briefly, at the postmodern society (a society preoccupied with spectacular media images) and its extravagant products. Within this context, extreme shoes have emerged as the epitome of post-modernity: their playful, unusual shapes break the conventional canons of aesthetic and practicality, in favor of eccentricity and shocking appearance. Through their curious 
shapes and design features, extreme shoes push and merge even further the alreadyblurred boundaries of fashion and art, and allow the wearers to shift from an ordinary (and perhaps fashionable) "self” to the extraordinary, extravagant “other”. Actually, as Daniel Miller points out, in the post-modern scenario, it is not only the clothing [the material culture of fashion] that is changing, but also the other side of the equation, the concept of the person, the sense of the self, the experience of being an individual (2010: 39).

As this initial research has shown, the desire to be playful and lead a captivating performance can overcome of the need to look beautiful. I believe that the charm of these eccentric, toy-like, curious shoes lays merely in visual consumption and satisfaction, which let women participate actively in an abstract process of social self-creation, redefinition and stabilization of their fashionable (but private) identities.

Through such shoes, women are exposed to a typology of objects that they usually long for and by which they are intrigued; they are a type of footwear that women may want to try on “just for fun” but may not want necessarily and impulsively to buy, because of their visual dissonances and unclear purpose. Extreme shoes, more than any other kind of shoes, materialize the idea of an empowering play and allude to the possibility of being unpredictable and different (not necessarily elegant or trendy), because of their unconventional features. By wearing them (or thinking about wearing them), women can choose new personas: they can play with these special objects and, through them, craft the fantasies of different (and perhaps more intriguing) intimate and sensual - yet 
unexpected - roles.

\section{Notes}

1. Levi, Kobi, “About me”, http://kobilevidesign.blogspot.co.uk/ (accessed March 3, 2014).

2. Ibid.; Kobi Levi, email message to Anna Catalani, November 3, 2013.

3. However, I am also acknowledging both the fashion industry discourse and the designer discourse.

4. This desire is emphasized in the society of the spectacle, because in it all social relationships are mediated by images.

5. Seven of the participants were based in the UK, while the other three participants were based in Italy. In order to maintain the anonymity of the interviewees, when quoting from their interviews, I have addressed them with "P” (for "Participant”), followed by an individual number and the date of their interv iew . 6. Marloes ten Bhömer is a Dutch-born designer, who has exhibited her work at international museums and galleries. Through her creations, ten Bhömer fuses artistic and technological experiment in order to discover shoes anew. Antonio Berardi is a British fashion designer of Sicilian descent, known primarily for his dresses. He has exhibited at fashion shows in London, Paris and Milan. His trademark style is known for being both 
traditional sensual. Kobi Levi is an Israeli-born designer who started designing, for his own leisure, shoes that challenge the standard definitions of design, art and fashion. In April 2010, Levi uploaded his creations to a blog that soon became extremely popular, attracting interest from all over the world. Currently Levi exhibits his work at national and international museums and events. Franc Fernandez is an Argentinean artist and fashion designer who has worked with many contemporary musical artists, including Lady Gaga (who wore at the 2010 MTV Video Music Awards the meat boots considered in this study), Sam Sparro, Scissor Sisters and Beyoncé Knowles. Aminaka Wilmont is a designer duo (Marcus Wilmont and Maki Aminaka Löfvander), known for their powerful and provocative shapes. In 2007 they won the London Fashion Fringe Award.

7.I started from the assumption that, as shoe-lovers and collectors, participants would be fascinated by the presented images and aspire to own at least a pair of extreme shoes. 8. Participants were clearly not keen at the idea of buying extreme shoes: while some of felt comfortable in spending up to $£ 200$ for a pair of shoes, they also explained that they would not spend a similar amount of money for extreme shoes because in some cases they could not understand how to wear the pair of shoes and therefore they would not see the benefit of wearing them.

\section{References}

Barker, Chris. 2012. Cultural Studies: Theory and Practice. London: SAGE.

Barnard, Malcom. 2002. Fashion as communication. London: Routledge.

Baudrillard, Jean. 2005. The system of objects. London and New York: Verso. 
Boodro, Michael. 1990. “Art \& Fashion: a fine romance”. Artnews, September: 120-27. Crane, D. 2001. Fashion and Its Social Agendas: Class, Gender, and Identity in Clothing. Chicago and London: The University of Chicago Press.

Dant, Tim. 1999. Material culture in the social world: values, activities, lifestyles. OUP. Debord, Guy. 2006. Society of the spectacle. London: Rebel Press.

Emberley, Julia .2001. "The ends of fashion; or, learning to theorize with shoes in the Bata Shoe Museum” in Footnotes: on shoes. S. Benstock and S. Ferriss (eds.) pp.17-40, New Brunswick: Rutgers University Press.

Evans, Caroline. 2007. Fashion at the Edge Spectacle, Modernity, and Deathliness. New Haven and London: Yale University Press.

Geczy, Adam and Karaminas, Vicki. 2012. "Fashion and art: critical crossovers”, in Fashion and Art, A. Geczy and V. Karaminas (eds.) pp. 1-12. London and New York: BERG.

Guy, Alison and Banim, Maura. 2000. “Personal collections: women’s clothing use and identity.” Journal of Gender Studies, 9 (3): 313-27.

Goffman, Erving. 1990. The presentation of self in everyday life. London: Penguin Books.

Harper, Douglas. 2002. “Talking about pictures: a case of photo elicitation.” Visual Studies, 17 (1): 13-26.

Hegarty, Paul. 2004. Jean Baudrillard: live theory. London: Continuum.

Huey, Sue and Proctor, Rebecca. 2007. New Shoes: Contemporary Footwear Design. London: Lawrence King Publishing Ltd.

Huizinga, Johan. 1971. Homo Ludens: a study of the play element in culture. Boston: 


\section{Beacon Press.}

Kawamura, Yuniya. 2004. Fashionology: An introduction to Fashion Studies. London and New York: BERG.

Miller, Daniel. 2010. Stuff. Cambridge and Malden: Polity Press.

Miller, Sanda. 2007. “Fashion as Art: is Fashion Art?” Fashion Theory, 11 (1): 25-40.

Pearce, Susan. 1997. “Foreword: words and things” in Experiencing material culture in the Western World, S. Pearce (ed.). pp.1-10. London and Washington: Leicester University Pres.

Riello, Giorgio and McNeil, Peter. 2006. Shoes: a history from sandals to sneakers. London and New York: BERG.

Ritzer, George. 1998. “Introduction”, in The Consumer Society: myths and structure, pp. 1-24. London: SAGE.

Steele, Valerie. 2012. “Fashion” in Fashion and Art, A. Geczy and V. Karaminas (eds.) pp. 13-28. London and New York: BERG.

Steele, Valerie and Hill, Colleen. 2012. Shoe obsession. New Haven and London: Yale University Press.

Sudjic, Deyan. 2009. The language of things: Design, Luxury, Fashion, Art: how we are seduced by the objects around us. London: Penguin Books.

Svendsen, Lars. 2006. Fashion: a philosophy. London: Reaktion Books Ltd.

Taylor, Melissa. 2005. “Culture Transition: Fashion's Cultural Dialogue between Commerce and Art”. Fashion Theory: The Journal of Dress, Body \& Culture, 9 (4): 445460.

Tseëlon, Efrat. 2001. Masquerades and Identities: Essays on Gender, Sexuality and 
Marginality. London: Routledge.

Vartanian, I. (ed.) 2012. High Heels. Fashion, Femininity, Seduction. Thames and Hudson.

Walters, Suzanna Danuta. 1994. Lives Together, Worlds Apart: Mothers and Daughters in Popular Culture. London, Berkeley and Los Angeles: University of California Press. Woodward, Ian. 2007. Understanding material culture. London: SAGE Publications Ltd. 


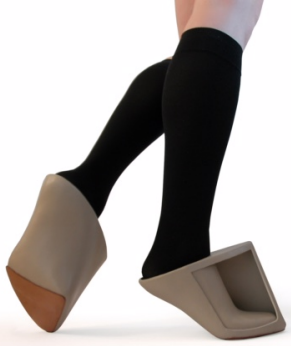




$$
\mathcal{L}
$$




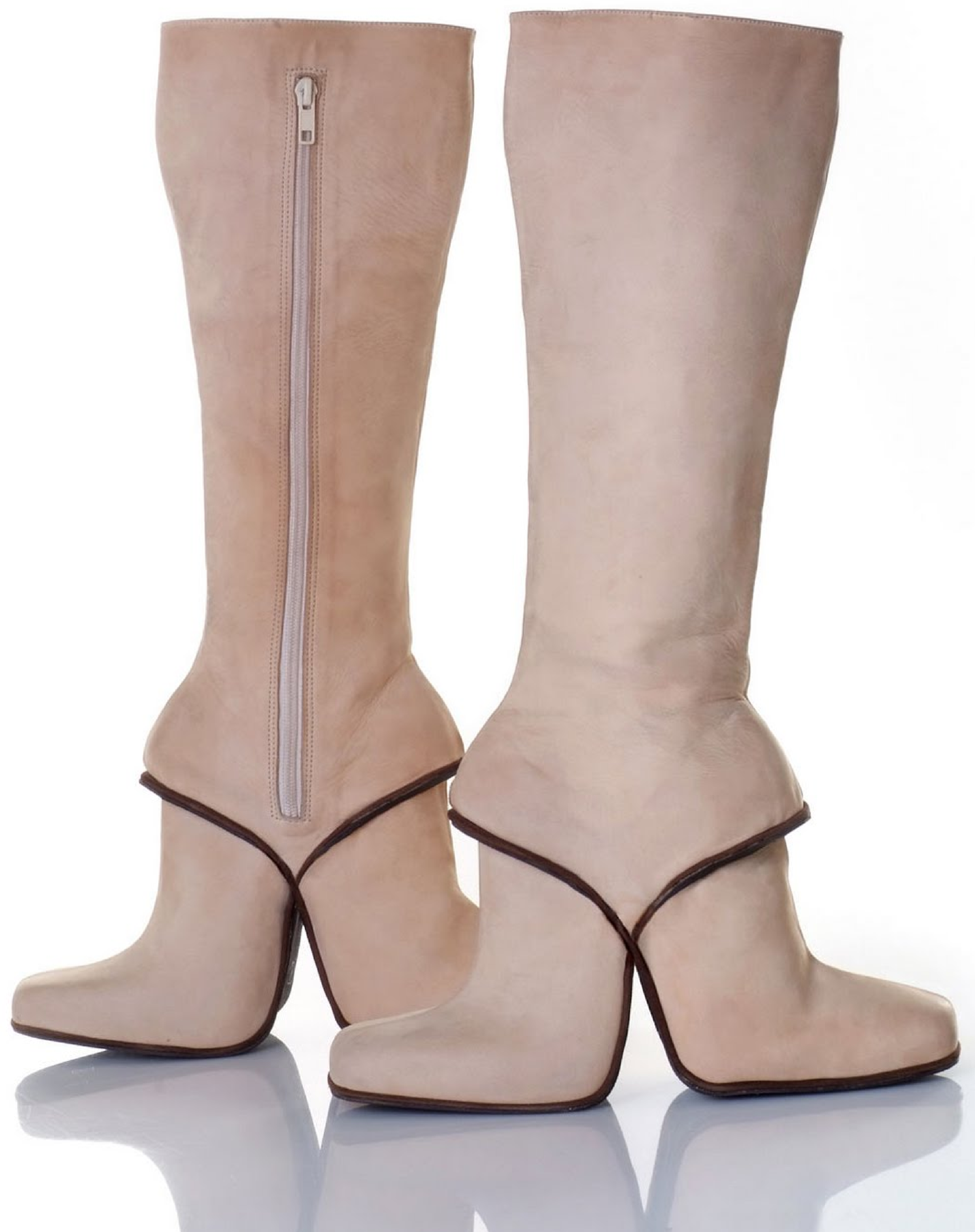




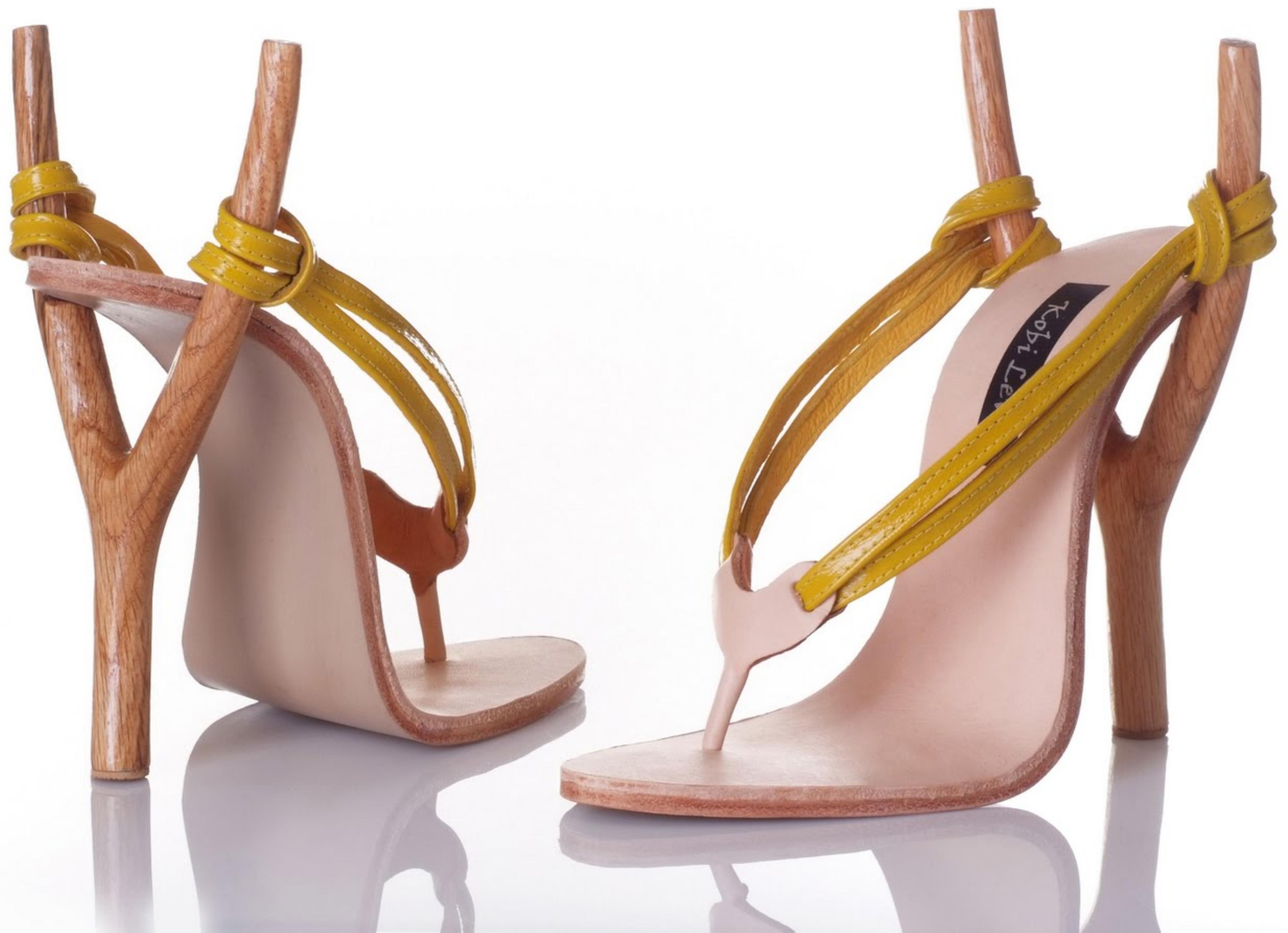




\section{Captions for figures}

Fig.1: Noheelsleathershoe; Designer: Marloes ten Bhömer; (C) Marloes ten Bhömer.

Fig.2: Toucan Shoes, Designer: Kobi Levi; C Kobi Levi.

Fig.3: Double Boot; Designer: Kobi Levi; (C) Kobi Levi.

Fig.4: Sling-Shot Shoes, Designer: Kobi Levi; (c) Kobi Levi. 